\title{
Cultivo de beterraba em ambientes protegido e natural na época de verão
}

\author{
João A. Tullio' ${ }^{1}$ Rosana F. Otto ${ }^{2}$, Adriane Boer ${ }^{1} \&$ Silvana Ohse $^{2}$
}

\begin{abstract}
RESUMO
Objetivou-se neste trabalho avaliar as respostas produtivas de beterraba cultivada em ambiente natural e sob túnel com malha de sombreamento durante a época de verão. O delineamento experimental foi blocos ao acaso com quatro repetições e os tratamentos arranjados em parcela sub-subdividida tendo, como fator primário, os ambientes de cultivo (protegido e natural), como fator secundário, as cultivares (Itapuã 202 e Tall Top Early Wonder) além das épocas de colheita (13, 26, 39, 52 e 65 dias após o transplante) como fator terciário. Foram avaliados número de folhas, fitomassas fresca e seca da parte aérea, fitomassa fresca da raiz tuberosa, índice de área foliar, altura da planta e presença ou não de aneis esbranquiçados na raiz tuberosa. Em cada ambiente de cultivo foram instalados sensores para medidas da radiação fotossinteticamente ativa e temperatura do ar. O cultivo de beterraba sob túnel resultou em menor fitomassa fresca da raiz tuberosa e maior fitomassa fresca da parte aérea quando comparadas àquelas do cultivo em ambiente natural. O cultivo de beterraba sob túnel coberto com telado preto $70 \%$ não apresentou vantagens em relação ao cultivo em ambiente natural no que diz respeito às características de produção e à qualidade da raiz de beterraba.
\end{abstract}

Palavras-chave: Beta vulgaris, túnel, sombrite, radiação, temperatura

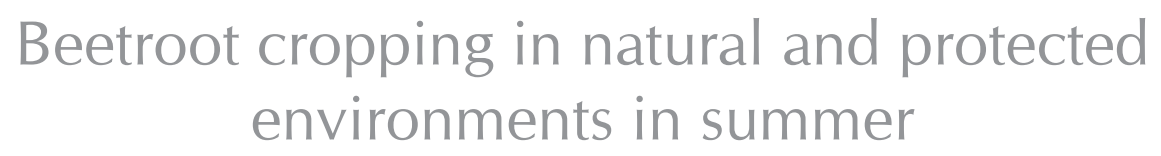

\begin{abstract}
The objective of the present study was to assess productive responses of beetroot cropped under natural conditions and under low tunnel covered with black net during the summer. The experimental design was a randomised complete-block arranged in a split-split-plot with 4 replications. The primary factor was cropping environment (protected and natural conditions), the secondary factor was beetroot cultivars (Itapuã 202 and Tall Top Early Wonder) and harvest time (13, 26, 39, 52 and 65 days after the transplant) was the tertiary factor. The characteristics assessed were the number of leaves, fresh and dry phytomass of leaves, fresh phytomass of tubers, leaf area index, plant height and presence or absence of white concentric lines in the tubers at each harvest time. Sensors were installed to measure photosynthetically active radiation and air temperature. Beetroot crop under tunnel resulted in lower fresh phytomass of the tuber and greater fresh phytomass of leaves when compared to the natural environment. The use of tunnel with black shade $70 \%$ did not show advantage over cultivation under natural environment in relation to production characteristics and beetroot qualities.
\end{abstract}

Key words: Beta vulgaris, tunnel, shade cover, radiation, temperature 


\section{INTRODUÇÃO}

A busca por dieta mais saudável tem contribuído para o aumento no consumo de hortaliças. Com isto, o desenvolvimento de sistemas de cultivo dessas espécies tem exigido esforços dos agricultores no sentido de minimizar ou até mesmo eliminar as deficiências do setor produtivo (Montezano \& Peil, 2006). É o caso do cultivo de beterraba que, no Brasil, representa 2,1\% do mercado de hortaliças (Nascimento, 2012).

A planta é cultivada, preferencialmente, na estação fria e/ ou em regiões com clima tropical de altitude, sendo tolerante à geada leve. Quando a planta cresce em temperaturas entre 16 e $20{ }^{\circ} \mathrm{C}$ verifica-se a formação de tubérculos de melhor qualidade (Puiatti \& Finger, 2005). Hoje, embora o cultivo da beterraba esteja adaptado a diversas condições ambientais, a produtividade é reduzida em até $50 \%$ quando cultivada no período de verão. As condições climáticas com maior umidade do ar e temperatura elevada favorecem a ocorrência de doenças e pragas e as raízes tuberosas adquirem coloração interna indesejável, com aneis concêntricos mais claros, além de o sabor ser alterado, tornando-se menos doce (Puiatti \& Finger, 2005).

$\mathrm{O}$ acúmulo de matéria seca na raiz da beterraba contínua ocorrendo mesmo com o declínio ou senescência das folhas, porém, o período de maior crescimento deste órgão coincide com o da parte aérea (Nunes et al., 1981). Desta forma, altos valores de índice de área foliar e da sua duração podem melhorar o aproveitamento da radiação incidente sobre a cultura contribuindo para o crescimento da raiz tuberosa.

A principal finalidade da produção em ambiente protegido é a obtenção de colheitas nas épocas em que há menor oferta do produto no mercado devido à dificuldade de produção em locais ou épocas cujas condições climáticas são desfavoráveis ao cultivo a céu aberto. Mesmo com o aumento no custo de produção, o cultivo em ambiente protegido atende às necessidades da entressafra e de consumidores mais exigentes em termos de qualidade do produto (Fontes et al., 1997) proporcionando maiores lucros ao produtor (Queiroga et al., 2001).

Para correção dos desajustes entre os fatores ambientais e as exigências climáticas, pode-se optar por sistemas de proteção da planta. Entre muitos, as telas de polipropileno (sombrite) vêm sendo cada vez mais utilizadas em condições de temperaturas altas, reduzindo a incidência direta dos raios solares nas espécies que necessitam de menor fluxo de energia radiante durante $\mathrm{o}$ crescimento (Queiroga et al., 2001).

$\mathrm{O}$ crescimento e o desenvolvimento normal das culturas ocorrem quando a quantidade de radiação recebida é superior ao limite trófico. Para a maioria das plantas este valor é de aproximadamente $8,4 \mathrm{MJ} \mathrm{m}^{-2} \mathrm{~d}^{-1}$, considerado o nível em que a planta produz o mínimo de fotoassimilados necessários à sua manutenção. Porém, para se determinar a viabilidade climática para o cultivo de hortaliças em determinada região é recomendável, além da radiação solar, levar em consideração também outras variáveis climáticas, como temperaturas do ar e do solo e umidade relativa do ar (FAO, 1990).

Por outro lado, sob radiação intensa poderá não haver aumento significativo do processo fotossintético se o ponto de saturação de fotossíntese da planta é atingido. Neste contexto, a velocidade de absorção do $\mathrm{CO}_{2}$ não é mais limitada pelas reações fotoquímicas, mas sim por reações enzimáticas e pela disponibilidade de $\mathrm{CO}_{2}$. Plantas $\mathrm{C} 3$ cultivadas, como a alface, apresentam ponto de saturação luminoso compreendido no intervalo de 1000 a $1500 \mu \mathrm{mol}$ fótons $\mathrm{m}^{-2} \mathrm{~s}^{-1}$ (Larcher, 2004).

O saldo de radiação no interior de ambiente protegido é menor que no ambiente externo em razão da barreira imposta pelo material de cobertura (Frisina \& Escobedo, 1999; Beckmann et al., 2006). Para as malhas, o efeito sobre a produção é variável dependendo da espécie e do local de cultivo. Em regiões mais quentes, as respostas produtivas geralmente são positivas (Bezerra Neto et al., 2005), devido à redução do excesso de radiação disponível.

Por outro lado, no sul do Brasil, a produtividade pode ser reduzida tanto em relação à massa fresca quanto ao número de produtos formados por planta como, por exemplo, em frutos do morangueiro. Isto ocorre em razão da baixa taxa de radiação verificada em alguns ambientes protegidos (Costa et al., 2011) e em algumas épocas do ano. No entanto, a exigência da cultura também traz respostas produtivas diferentes (Otto et al., 2000).

Durante o período de verão verifica-se redução na oferta de beterraba no mercado em virtude do excesso de temperatura para cultivo e ao volume excessivo de precipitação. O uso de sistema de proteção do cultivo nessa época pode amenizar o problema, motivo pelo qual se objetivou avaliar as respostas produtivas de duas cultivares de beterraba cultivadas em ambiente natural e sob túnel com tela, durante o verão de Ponta Grossa, PR.

\section{Material e Métodos}

O experimento foi conduzido na área experimental da Universidade Estadual de Ponta Grossa, PR, localizada a $25^{\circ} 05^{\prime} 37^{\prime \prime}$ de latitude sul, $50^{\circ} 03^{\prime} 33^{\prime \prime}$ de longitude a oeste de Greenwich e altitude de 990 m, em solo tipo Cambissolo Háplico Tb Distrófico e textura argilosa. O período de cultivo foi de 24/10/2010 a 28/01/2011.

O preparo da área consistiu no destorroamento do solo com enxada rotativa e no levantamento de canteiros. Utilizou-se, durante todo ciclo da cultura, a irrigação por aspersão.

As mudas de beterraba foram produzidas na estufa em bandejas de poliestireno expandido, com 200 células, usandose substrato comercial e transplantadas aos 31 dias após a semeadura (DAS) quando apresentavam três folhas definitivas. O espaçamento utilizado foi $10 \times 30 \mathrm{~cm}$, distribuído em parcelas experimentais de $1,20 \times 3,50 \mathrm{~m}$, para ambas as cultivares.

O delineamento experimental foi blocos casualizados com 4 repetições cujos tratamentos foram distribuídos em parcelas sub-subdivididas. Os fatores principal, secundário e terciário foram, respectivamente, ambientes de cultivo (túnel baixo com tela preta $70 \%$ e ambiente natural), cultivares [Tall Top Early Wonder (EWTT - Sakata) e Itapuã 202 (Isla)] e épocas de colheita $(13,26,39,52$ e 65 dias após o transplante - DAT).

No túnel baixo foram usados arcos de PVC ( $(1 / 2)$ enterrados $30 \mathrm{~cm}$ de cada extremidade nas laterais do canteiro, espaçados entre si em $1,50 \mathrm{~m}$. A altura no ponto central do arco até a superfície do solo foi de $1,00 \mathrm{~m}$ e para a cobertura do túnel foi utilizada tela preta $70 \%$ (sombrite). 
Em cada época foram colhidas seis plantas por tratamento aos 13, 26, 39, 52 e 65 dias após o transplante (DAT). As características avaliadas foram número de folhas $(>3 \mathrm{~cm}$ de comprimento), altura da planta (cm), fitomassas fresca e seca da parte aérea - pecíolo e limbo foliar $\left(\mathrm{g} \mathrm{planta}^{-1}\right)$, fitomassa fresca da raiz tuberosa (g) e o índice de área foliar (IAF). Aos 65 DAT foram avaliadas a produtividade e a presença ou ausência de aneis claros no interior das raízes tuberosas. Nas determinações das fitomassas fresca (FFPA) e seca da parte aérea (FSPA) e da fitomassa fresca da raiz tuberosa (FTub) usou-se balança de precisão. Para FSPA, as plantas foram secadas em estufa de circulação de ar forçada a $60{ }^{\circ} \mathrm{C}$ até atingirem massa constante. A medida da área foliar da planta (AF) foi realizada por meio do medidor de área foliar LICOR 3100C e os dados foram utilizados para determinação do IAF pela fórmula $\mathrm{IAF}=\mathrm{AF} /$ ESP, em que ESP = espaçamento entre plantas.

Em cada ambiente de cultivo foram instalados sensores para medidas da radiação solar fotossinteticamente ativa (PAR) e da temperatura do ar (20 $\mathrm{cm}$ de altura do solo). Para as medidas foram utilizados os sensores LI190SB (LiCor Quantum Sensor) e os termopares (107 Temperature probe - Campbell Sci) respectivamente. Os sensores foram conectados a um sistema de aquisição de dados (CR23x, Campbell Sci.) e programados para realização de medidas a cada minuto e armazenamento das médias horárias.

Os dados de PAR foram registrados em unidade de medida instantânea $\left(\mu \mathrm{mol} \mathrm{s}{ }^{-1} \mathrm{~m}^{-2}\right)$ e integralizados em mol m$~^{-2} \mathrm{~d}^{-1}$, adotando-se a Eq. 1:

$$
\operatorname{PAR}=\left\{\sum \text { diárioPARt }(\mathrm{s})\right\} 10^{-6}
$$

em que:

t - corresponde ao tempo entre as coletas

Para fins de comparação os dados de PAR foram transformados em $\mathrm{MJ} \mathrm{m}^{-2} \mathrm{~d}^{-1}$, utilizando-se um valor de conversão conforme Thimijan \& Heins (1983) por meio da Eq. 2:

$$
\mathrm{PAR}=\sum \text { diário }\left\{\operatorname{PAR}\left(\mu \mathrm{mol} \mathrm{s}^{-1} \mathrm{~m}^{-2}\right) \mathrm{t}(\mathrm{s}) / 4,57\right\} 10^{-6}
$$

sendo 4,57 o valor de conversão (Beckmann et al., 2006).

Os dados foram submetidos à análise de variância utilizandose o software SISVAR 4.6 (Ferreira, 2011) e, para comparação de médias, o teste Tukey, a $5 \%$ de probabilidade. A análise de regressão foi realizada para determinação de modelos que representavam interação entre os fatores estudados, utilizando-se o programa Excel 2007; enfim, os dados foram transformados em

$$
\sqrt{x+0,5}
$$

\section{Resultados e Discussão}

Para as características estudadas não houve interação significativa entre ambientes de cultivo, cultivares e épocas de colheita. Também não houve interação entre os fatores cultivares $\mathrm{x}$ épocas de colheita e entre cultivares $\mathrm{x}$ ambientes de cultivo. No entanto, a interação entre ambientes de cultivo x épocas de colheita foi significativa para todas as características, exceto para fitomassa seca da parte aérea da planta.

Considerando os resultados encontrados para as plantas cultivadas nos diferentes ambientes ao longo do ciclo, a fitomassa fresca da raiz tuberosa (FTub) apresentou desenvolvimento semelhante entre os ambientes até os 52 DAT (Figura 1A). Na sequência, verificou-se crescimento da
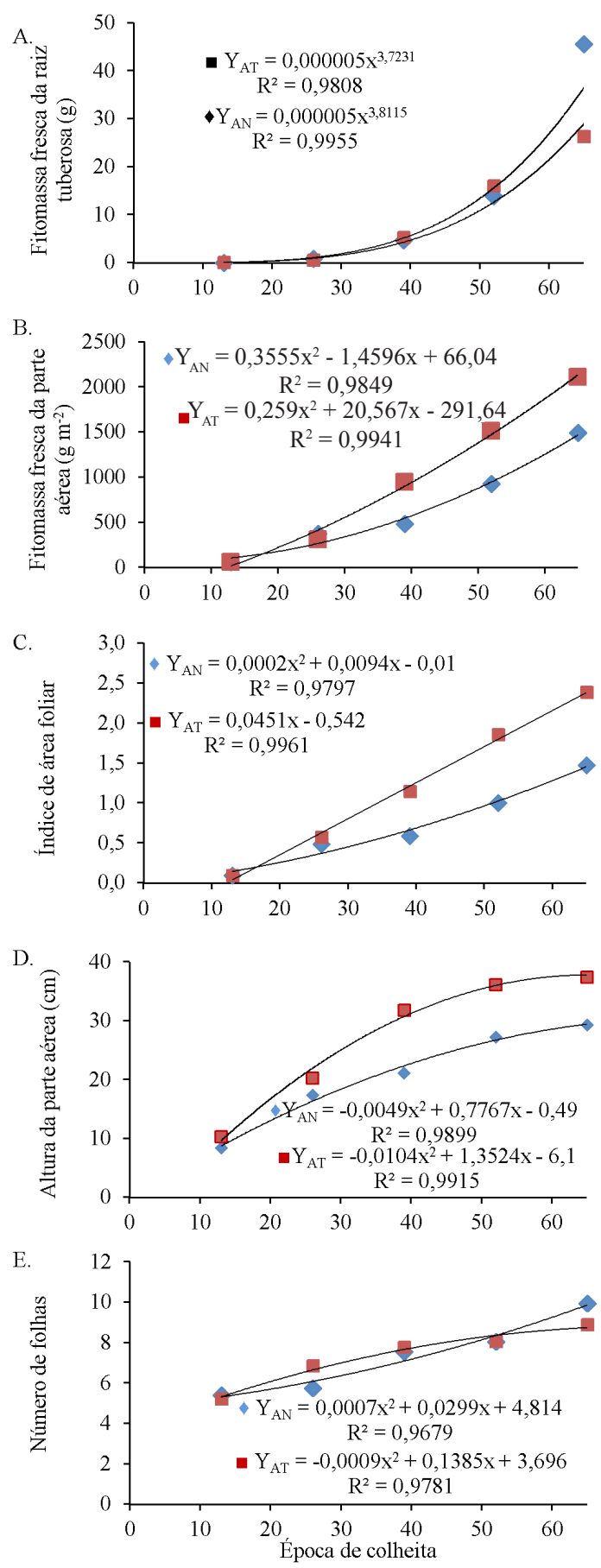

Figura 1. Fitomassas frescas da raiz tuberosa (A) e da parte aérea (B), índice de área foliar (C), altura da planta (D) e número de folhas (E) de plantas de beterraba em função dos sistemas de cultivo e das época de colheita (dias após transplantio - DAT) 
raiz tuberosa mais acelerado no ambiente natural (AN) em relação ao cultivo sob túnel com sombrite (AT); aos 65 DAT a FTub foi reduzida em $30 \%$ pelo sombreamento resultante do uso do túnel reduzindo significativamente o tamanho das raízes, resultado este relacionado com a baixa intensidade de radiação PAR incidente no ambiente do túnel, sobretudo em dias nublados (Figura 2A).

Constatou-se que, na última colheita, as produtividades da raiz de beterraba foram de 15,1 e $9,1 \mathrm{t} \mathrm{ha}^{-1}$ para AN e $\mathrm{AT}$, respectivamente, sendo inferiores à média nacional que oscila entre 20 e $35 \mathrm{t} \mathrm{ha}^{-1}$ (Sediyama et al., 2011). A baixa produtividade foi devido à ocorrência de alta precipitação durante o ciclo $(589 \mathrm{~mm})$, com várias horas de nebulosidade, o que contribuiu para a diminuição da radiação PAR incidente disponível para as plantas.

A disponibilidade da radiação solar no interior de ambientes protegidos é menor em relação ao ambiente externo em razão da reflexão e da absorção pelo material de cobertura (Beckmann et al., 2006). Segundo a FAO (1990), o limite de radiação incidente abaixo do qual as plantas não produzem o mínimo de fotoassimilados necessários à sua manutenção (definido como limite trófico) é de $8,4 \mathrm{MJ} \mathrm{m}^{-2} \mathrm{~d}^{-1}$. Segundo a equação determinada por Hora (2006) para condições naturais, a radiação fotossinteticamente ativa (PAR) corresponde a $45 \%$ desse valor $\left(3,8 \mathrm{MJ} \mathrm{m}^{-2} \mathrm{~d}^{-1}\right)$. O túnel com sombrite (AT)
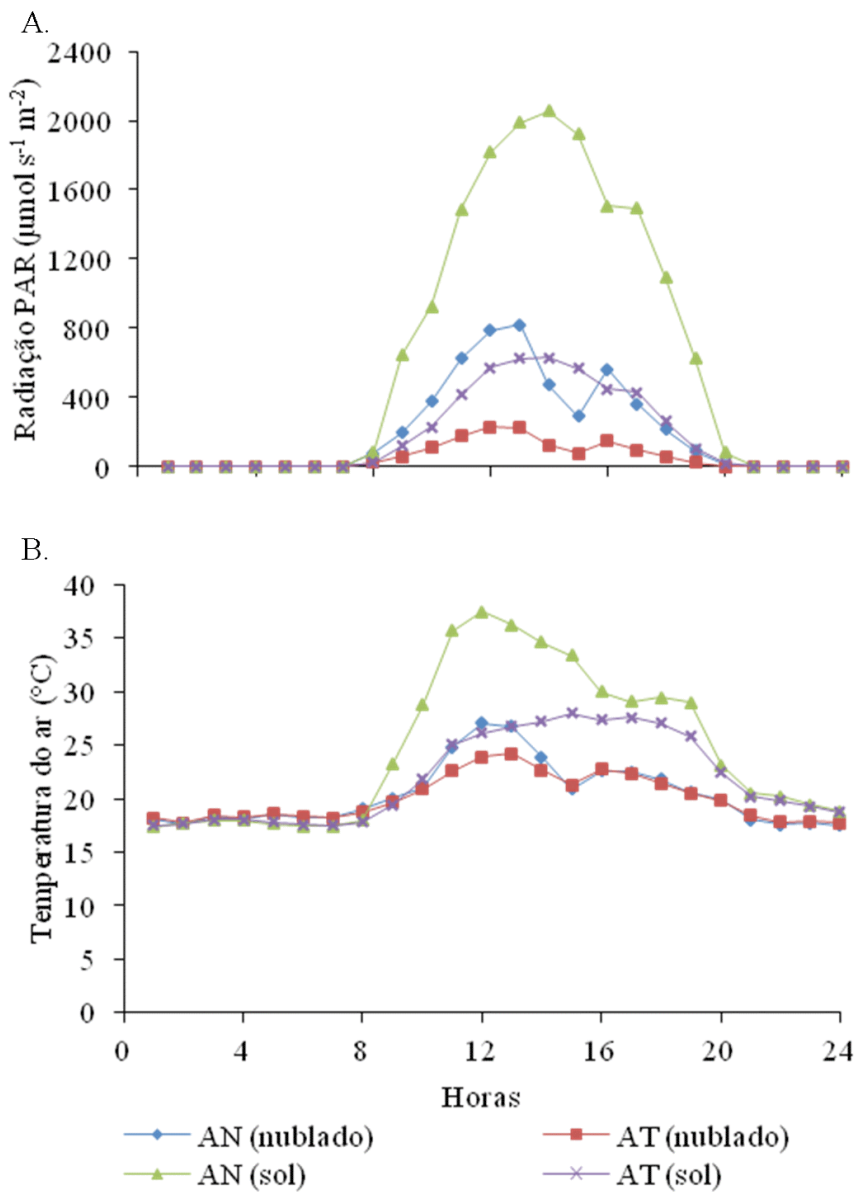

Figura 2. Radiação fotossinteticamente ativa (PAR) (A) e temperatura do ar (B) nos ambientes natural (AN) e sob túnel (AT) em dias ensolarado (62 DAT) e nublado (58 DAT) apresentou transmissividade média de $28 \%$ independente de o dia estar ensolarado ou nublado (Figura 2A). Isto significa que, mesmo nos poucos dias ensolarados, os valores de PAR sob o túnel com sombrite foram de no máximo $3,5 \mathrm{MJ} \mathrm{m}^{-2} \mathrm{~d}^{-1}$ (dados não apresentados) estando abaixo dos valores mínimos propostos pela FAO (1990). Para dias nublados e chuvosos, os valores chegaram a $1,1 \mathrm{MJ} \mathrm{m}^{-2} \mathrm{~d}^{-1}$ (Figura $\left.2 \mathrm{~A}\right)$. A consequência foi a redução da produtividade das plantas.

Segundo Larcher (2004), o efeito de baixos valores de PAR pode ser limitante não apenas na produção da estrutura vegetativa da planta, mas, principalmente no direcionamento de quantidade reduzida de fotoassimilados para a formação de frutos, uma vez que sua maior parte é gasta na respiração.

Resultados semelhantes obtiveram Otto et al. (2000) na Espanha, com o cultivo da alface em ambiente natural e sob agrotêxtil, ao verificar que na maior parte do ciclo da alface os valores de PAR diário foram baixos $\left(<5 \mathrm{MJ} \mathrm{m}^{-2} \mathrm{~d}^{-1}\right)$ devido à baixa elevação solar naquela época do ano (novembro) e aos frequentes dias nublados e chuvosos do período. As plantas sob agrotêxtil apresentaram alongamento dos entrenós resultando em formação de cabeça defeituosa. De acordo com os autores, o uso de agrotêxtil para proteção de plantas não resultou em técnica de cultivo adequada devido à limitação de radiação, ainda que tenha proporcionado efeito benéfico do incremento da temperatura do ar e do solo.

Durante os meses de verão, a radiação solar pode atingir facilmente níveis acima do adequado para as plantas, resultando em altas temperaturas do ar. No experimento, os valores de temperatura do ar noturnos foram semelhantes para ambos os ambientes de cultivo caracterizando que, mesmo que ocorram modificações da temperatura durante o dia entre AN e AT, essas diferenças se anulam durante a noite. $\mathrm{O}$ resultado foi temperaturas médias diárias de $20^{\circ} \mathrm{C}$ em dias nublados, tanto para AN quanto para AT (Figura 2B) considerados valores próximos da faixa ideal $\left(16 \mathrm{a} 20^{\circ} \mathrm{C}\right)$ para a produção de raízes tuberosas de qualidade, sem a formação de aneis esbranquiçados (Puiatti \& Finger, 2005).

Em dias ensolarados o uso do túnel com sombrite reduziu a temperatura máxima diária em até $10{ }^{\circ} \mathrm{C}$ comparada com a do ambiente natural (Figura 2B) mas as temperaturas médias diárias foram de 24,6 e 22, $1^{\circ} \mathrm{C}$ para AN e AT, respectivamente. Mesmo que esses valores tenham sido superiores ao considerado ideal na formação da raiz tuberosa, não foi constatada a formação de aneis brancos concêntricos nas raízes devido, provavelmente, aos poucos dias ensolarados que ocorreram durante o ciclo da cultura, condição em que as diferenças entre as temperaturas máximas do dia não ultrapassam $3{ }^{\circ} \mathrm{C}$ (Figura $2 \mathrm{~B}$ ).

$\mathrm{O}$ período de maior crescimento da raiz tuberosa coincide com o período de maior crescimento da parte aérea (Nunes et al., 1981). Para beterraba, até que as primeiras folhas sejam formadas, o crescimento da raiz tuberosa é lento, caracterizando pouco acúmulo de fotoassimilados. Até 26 DAT ambos os ambientes de cultivo apresentaram desenvolvimento semelhante para a FFPA (Figura 1B), IAF (Figura 1C) e AP (Figura 1D), mas após esta data, a FFPA em AN foi menor que em AT, caracterizando resultado inverso ao encontrado para FTub (Figura 1A). 
O resultado está relacionado ao estiolamento das folhas das plantas sob AT, cujos baixos níveis de radiação disponíveis para as plantas levaram à expansão do limbo foliar pelo armazenamento de água nas células (Lacher, 2004). A ocorrência do estiolamento pode ser verificada quando se comparam os valores de FFPA e FSPA, em que o aumento da FSPA foi semelhante para ambos os ambientes de cultivo (Tabela 1) diferindo dos resultados encontrados para FFPA (Figura 1B). Isso significa que o aumento da FFPA em AT comparado ao AN não correspondeu ao aumento dos fotoassimilados e sim, ao acúmulo de água caracterizando estiolamento da planta, em razão do baixo nível de radiação PAR disponível sob AT; como consequência do estiolamento, o limbo foliar apresentou-se tenro, perdendo a turgidez após a colheita.

Gondim et al. (2007) observaram mudanças na morfologia das plantas de taro ao longo do ciclo, com aumento da área foliar e alongamento do pecíolo para culturas cultivadas na sombra, como os resultados encontrados para IAF das plantas cultivadas sob o túnel (Figura 1C). A expansão da folha sob baixa luminosidade é frequentemente relatada e caracteriza o recurso utilizado pela planta para compensar ou imprimir melhor aproveitamento a baixa luminosidade (Paez et al., 2000; Lima et al., 2008).

Inicialmente, o número de folhas (NF) foi semelhante entre os ambientes avaliados; entretanto, ao final do ciclo (65 DAT) as plantas cultivadas em AN apresentaram maior NF comparadas àquelas cultivadas em AT (Figura 1E) caracterizando desenvolvimento das plantas em razão das condições microclimáticas mais favoráveis ao cultivo em AN.

Não houve interação entre Cultivares e épocas de colheita, bem como para Cultivares e Ambientes de Cultivo para nenhuma das características avaliadas (Tabela 1).

As plantas da cultivar Itapuã 202 apresentaram porte maior que a cultivar EWTT caracterizado pelas diferenças encontradas em FFPA, NF e IAF (Tabela1); no entanto, as diferenças não

Tabela 1. Altura das plantas (AP), fitomassas fresca (FFPA) e seca (FSPA) da parte aérea, número de folhas (NF), fitomassa fresca da raiz tuberosa (FTub) e Índice de área foliar (IAF), das plantas de beterraba em função dos ambientes de cultivo, das cultivares e das épocas de colheita de plantas

\begin{tabular}{|c|c|c|c|c|c|c|}
\hline & \multirow{2}{*}{$\begin{array}{l}\text { AP } \\
(\mathrm{cm})\end{array}$} & FFPA & FSPA & \multirow{2}{*}{ NF } & \multirow{2}{*}{$\begin{array}{c}\text { FTub } \\
\text { (g) }\end{array}$} & \multirow{2}{*}{ IAF } \\
\hline & & \multicolumn{2}{|c|}{$\left(g \mathrm{pl}^{-1}\right)$} & & & \\
\hline \multicolumn{7}{|l|}{ Ambiente } \\
\hline Tunel & $27,3 a^{*}$ & $29,8 \mathrm{a}$ & $2,16 \mathrm{a}$ & $7,4 \mathrm{a}$ & $9,6 \mathrm{~b}$ & $1,21 \mathrm{a}$ \\
\hline AN & $20,8 \mathrm{~b}$ & $20,1 \mathrm{a}$ & $1,85 \mathrm{a}$ & $7,4 \mathrm{a}$ & $13,1 \mathrm{a}$ & $0,73 \mathrm{~b}$ \\
\hline C.V. (\%) & 11,5 & 33,9 & 30,2 & 4,4 & 14,6 & 19,8 \\
\hline \multicolumn{7}{|l|}{ Cultivar } \\
\hline Itapuã 202 & $24,7 \mathrm{a}$ & $27,5 \mathrm{a}$ & $2,20 \mathrm{a}$ & $7,6 \mathrm{a}$ & $11,3 \mathrm{a}$ & $1,09 a$ \\
\hline EWTT & $23,4 \mathrm{a}$ & $22,3 b$ & $1,80 \mathrm{a}$ & $7,1 \mathrm{~b}$ & $11,5 \mathrm{a}$ & $0,86 b$ \\
\hline C.V. $(\%)$ & 4,4 & 16,1 & 12,7 & 4,4 & 22,9 & 11,2 \\
\hline \multicolumn{7}{|l|}{ Épocas de colheita } \\
\hline E1 & $9,5 d$ & $1,9 \mathrm{e}$ & $0,14 \mathrm{e}$ & $5,3 d$ & $0,09 \mathrm{~d}$ & $0,10 \mathrm{e}$ \\
\hline E2 & $18,9 \mathrm{c}$ & $10,4 d$ & $0,76 \mathrm{~d}$ & $6,3 \mathrm{c}$ & $0,77 \mathrm{~d}$ & $0,54 \mathrm{~d}$ \\
\hline E3 & $26,6 \mathrm{~b}$ & $21,6 \mathrm{c}$ & $2,15 \mathrm{c}$ & $7,7 \mathrm{~b}$ & $4,99 \mathrm{C}$ & $0,87 \mathrm{C}$ \\
\hline E4 & $31,8 \mathrm{a}$ & $36,7 \mathrm{~b}$ & $2,84 \mathrm{~b}$ & $8,1 \mathrm{~b}$ & $15,05 b$ & $1,43 b$ \\
\hline E5 & $33,4 \mathrm{a}$ & $54,1 \mathrm{a}$ & $4,12 \mathrm{a}$ & $9,4 \mathrm{a}$ & $35,99 \mathrm{a}$ & $1,94 \mathrm{a}$ \\
\hline CV (\%) & 4,7 & 15,8 & 12,5 & 4,1 & 28,3 & 10,2 \\
\hline
\end{tabular}

resultaram em aumento da FTub (Tabela 1) pelas razões já discutidas anteriormente. Segundo os catálogos das empresas que comercializam as cultivares avaliadas, as plantas possuem excelente desenvolvimento foliar, porém, EWTT tem pequena inserção foliar apresentando, assim, menor NF que a Itapuã 202 (Tabela 1).

Para todas as características avaliadas verificou-se crescimento contínuo das plantas ao longo do ciclo de cultivo, caracterizado pelo aumento dos valores de todas as avaliações nas diferentes épocas de colheita (Tabela 1).

\section{CONClusões}

1. Para o verão chuvoso de Ponta Grossa, o cultivo de beterraba sob túnel coberto com tela de sombreamento preta (tipo sombrite) $70 \%$ não apresentou vantagens em relação ao cultivo em ambiente natural, no que se refere às características de produção e à qualidade da raiz tuberosa, independente da cultivar.

2. Em dias ensolarados, o uso do túnel coberto com tela de sombreamento preta a $70 \%$ reduz a temperatura máxima em até $10^{\circ} \mathrm{C}$ comparado ao ambiente natural.

\section{Literatura Citada}

Bezerra Neto, F.; Rocha, M. Z.; Rocha, R. H.; Queiroga, R. C. F. Produtividade de alface em função de condições de sombreamento e temperatura e luminosidade elevadas. Horticultura Brasileira, v.23, p.189-192, 2005.

Beckmann, M. Z.; Duarte, G. R. B.; Paula, V. A.; Mendez, M. E. G.; Peil, R. E. G. Radiação solar em ambiente protegido cultivado com tomateiros nas estações verão-outono do Rio Grande do Sul. Ciência Rural, v.36, p.86-92, 2006.

Costa, R. C; Calvete, E. O; Reginatto F. H.; Cecchetti, D.; Loss, J. T.; Rambo, A.; Tessaro, F. Telas de sombreamento na produção de morangueiro em ambiente protegido. Horticultura Brasileira, v.29, p.98-102, 2011.

FAO - Food and Agriculture Organization of the United Nations. Protected cultivation in the Mediterranean climate. Rome: FAO, 1990. 313p. FAO Plant Production and Protection Paper, 90

Ferreira, D. F. Sisvar: A computer statistical analysis system. Ciência e Agrotecnologia, v.35, p.1039-1042, 2011.

Fontes, P. C. R.; Dias, E. N.; Zanin, S. R.; Finger, F. L. Produção de cultivares em tomate em estufa coberta com plástico. Revista Ceres, v.44, p.152-160, 1997.

Frisina, V. A.; Escobedo, J. F. Balanço de radiação e energia da cultura de alface em estufa de polietileno. Pesquisa Agropecuária Brasileira, v.34, p.1775-1786, 1999.

Gondim, A. R. de O.; Puiatti, M.; Cecon, P. R.; Finger, F. L. Crescimento, partição de fotoassimilados e produção de rizomas de taro cultivado sob sombreamento artificial. Horticultura Brasileira, v.25, p.418-428. 2007.

Hora, R. C. Avaliação da cultura do pepineiro japonês enxertado e não enxertado, cultivado em diferentes ambientes. Botucatu, UNESP, 2006. 68p. Tese Doutorado

Larcher, W. Ecofisiologia Vegetal. São Carlos: Rima Editora, 2004. 531p. 
Lima, J. D.; Silva, B. M. da S. E.; Moraes, W. da S.; Dantas, V. A. V.; Almeida, C. C. Efeitos da luminosidade no crescimento de mudas de Caesalpinia ferrea Mart. ex Tul. (Leguminosae, Caesalpinoideae). Acta Amazônica, v.38, p.5-10, 2008.

Montezano, E. M.; Peil, R. M. N. Sistemas de consórcio na produção de hortaliças. Revista Brasileira de Agrociência, v.12, p.129-132, 2006.

Nascimento, W. M. Perspectivas de produção de sementes de beterraba no Brasil. 2012. <http://www.abcsem.com.br/ noticia.php?cod=2400>. 11 Jun. 2012.

Nunes, M. A.; Dias, M. A.; Gaspar, A. M.; Oliveira, M. D.; Pinto, E.; Carapau, A. L. Análise do crescimento da beterraba sacarina em cultura de primavera. Agronomia Lusitana, v.40, p.217-240, 1981.

Otto, R. F.; Gimenez, C; Castilla, N. Modificações microclimáticas sob proteção de polipropileno cultivado com espécies hortícolas em Córdoba, Espanha. Horticultura Brasileira, v.18, p.204-211, 2000.
Paez, A.; Paz, V.; Lóppez, J. C. Crecimiento y respuestas fisiológicas de plantas de tomate cv. Rio Grande en la época mayo-julio. Efecto del sombreado. Revista da Faculdade de Agronomia, v.17, p.173-184, 2000.

Puiatti, M.; Finger, F. L. Cultura da beterraba. In: Fontes, P. C. R. (ed.). Olericultura: teoria e prática. Viçosa. 2005. p.345-354.

Queiroga, R. C. F.; Bezerra, Neto F.; Negreiros, M. Z.; Oliveira, A. P.; Azevedo, C. M. S. B. Produção de alface em função de cultivares e tipos de tela de sombreamento nas condições de Mossoró. Horticultura Brasileira, v.19, p.192-196, 2001.

Sediyama, M. A. N.; Santos, M. R.; Vidigal, S. M.; Salgado, L. T. Produtividade e exportação de nutrientes em beterraba cultivada com cobertura morta e adubação orgânica. Revista Brasileira de Engenharia Agrícola e Ambiental, v.15, p.883889, 2011.

Thimijan, J. R. W.; Heins, R. D. Photometric, radiometric and quantum light units of measure: A review of procedures for interconversion. HortScience, v.18, p.818-822, 1983. 